\title{
PENGEMBANGAN PEMASARAN KOPI GALUNGGUNG MENGGUNAKAN SISTEM E-COMMERCE
}

\author{
MARKETING DEVELOPMENT IN GALUNGGUNG COFFEE USING \\ E-COMMERCE SYSTEM
}

\author{
Dona Setia Umbara*, Missi Hikmatyar \\ Universitas Perjuangan Tasikmalaya, Jl. Pembela Tanah Air No. 177 Tasikmalaya \\ *E-mail: donasetia@unper.ac.id \\ (Diterima 15-11-2019; Disetujui 16-12-2019)
}

\begin{abstract}
ABSTRAK
Proses pemasaran pintu ke pintu tradisional telah menjadi masalah dalam distribusi kopi galunggung. Kemudian perlu ada terobosan oleh pemangku kepentingan atau pengusaha lokal yang bekerja sama dengan petani dalam sistem pemasaran yang tepat dalam distribusi kopi Galunggung. Tujuan khusus dari penelitian ini adalah untuk memperluas pemasaran bisnis kopi Galunggung dengan mengembangkan sistem online dalam bentuk E-commerce. Tahapan penelitian ini meliputi analisis kebutuhan yaitu mempersiapkan semua kebutuhan yang berkaitan dengan penelitian yang akan dilakukan. Tahap selanjutnya adalah desain yang meliputi desain sistem pemasaran konvensional dan desain sistem pemasaran e-commerce. Berdasarkan hasil pemasaran produk di media sosial, 1.121 orang melihat iklan produk kopi parentas, dan $98 \%$ akun yang tidak mengikuti akun kopi parentas. Pemasaran produk kopi di sistem e-commerce meliputi akun yang tidak diketahui yang memiliki minat pada kopi. ada hasil dari rentang usia yang melihat iklan produk di media sosial. Usia 24-34 memiliki lebih banyak minat pada kopi, usia 18-24 yang memiliki minat kedua terbanyak pada kopi dan berusia 35-44 memiliki sedikit minat dalam kopi. Jadi untuk melakukan pemasaran kopi lebih baik dipasarkan untuk kisaran usia 24-34.
\end{abstract}

Kata kunci: kopi, galunggung, pemasaran, e-commerce

\section{ABSTRACT}

The traditional door to door marketing process has become a problem in the distribution of galunggung coffee. Then there needs to be a breakthrough by local stakeholders or entrepreneurs who work closely with farmers in the right marketing system in the distribution of Galunggung coffee. The specific purpose of this research is to expand the marketing of the Galunggung coffee business by developing an online system in the form of E-commerce. The stages of this research include a needs analysis that is preparing all needs related to the research to be conducted. The next stage is the design which includes the design of conventional marketing systems and the design of e-commerce marketing systems. Based on the results of marketing the product on social media, 1,121 people saw parentas product advertisements, and $98 \%$ of accounts that did not follow a coffee parentas account. So, marketing coffee products includes an unknown account that has an interest in coffee. there is the result of the age range that sees product advertisements on social media. Ages 24-34 have more interest in coffee after age 18-24 who have an interest in coffee and aged 35-44 have little interest in coffee. So to do better marketing in the age range 24-34.

Keywords: coffee, galungung, marketing, e-commerce 


\section{PENDAHULUAN}

Kopi galunggung termasuk dalam komoditas jenis kopi yang menjadi identitas di Kota Tasikmalaya. Kopi ini masuk dalam golongan berjenis Arabika karena ditanam di lereng pegunungan galunggu dengan ketinggian 1.125 mdpl. Persebaran kopi galunggung belum terdistribusikan secara menyeluruh di Tasikmalaya. Sehingga kopi galunggung tersisihkan oleh kopi-kopi daerah lain seperti kopi Gayo Aceh, Mandaling Sumatra, dan Bali Kintamani yang dipasarkan di Tasikmalaya. Persebaran yang kurang menyeluruh menyebabkan kopi Galunggung belum banyak dikenal oleh dunia bahkan masyarakat Tasikmalaya itu sendiri. Proses pemasaran yang secara tradisional door to door menjadi suatu permasalahan dalam pendistribusian kopi galunggung. Maka perlu adanya terobosan oleh para stakeholder atau pengusaha lokal yang bekerja sama dengan petani dalam sistem pemasaran yang tepat dalam pendistribusian kopi galunggung.

Pengembangan pemasaran kopi di Indonesia dapat menggunakan metode tradisional dan kemitraan (Sugiarti, 2010). Proses pemasaran kopi sudah dilakukan dengan cara bekerja sama dengan coffee shop "Balarea Kopi" yang ada di Tasikmalaya. Sistem ini masih menggunakan sistem tradisional. Metode pemasaran kopi yang sering digunakan dalam industri skala kecil yaitu pasar nonlelang. Namun petani kopi Galunggung belum memanfatakan adanya distributor. Sistem agribisnis dapat berjalan dengan baik ketika sistem agribisnisnya dapat berjalan dengan fleksibel yang mampu menerima perubahan dalam pengembangan usaha kopi nya. Sehingga perlu dilakukan sistem pengembangan pemasaran yang menggunakan sistem online.

Sistem E-Commerce adalah salah satu sistem pemasaran online yang belum banyak digunakan dalam metode penjualan. Aplikasi E-commerce dapat dilakukan secara lebih cepat, lebih intensif, dan lebih murah daripada aplikasi prinsip manajemen secara konvensional (door to door, one-to-one relationship) hubungan antar perusahaan dengan entitas eksternal lainnya (pemasok, distributor, rekanan, konsumen) (Fahmi, Baihaqi, \& Kadir, 2013).

Pada tahun 2016, luasan area perkebunan kopi di jawa barat mencapai angka 32.497 Ha dengan jumlah total produksi mencapai 17.670 ton (Fahmi et al., 2013). Kabupaten Tasikmalaya 
merupakan salah satu daerah penghasil kopi di jawa barat khususnya di kaki gunung Galunggung. Varietas kopi galunggung berjenis arabika sesuai dengan karakteristik kopi arabika yang tumbuh pada ketinggian lebih dari 1000 mdpl. Sistem pemasaran kopi Galunggung masih bersifat tradisional dengan cara penjualan person to person yang hanya menjangkau konsumen tertentu. Hal ini menyebabkan kopi galunggung belum begitu terkenal di kalangan penikmat kopi, maka perlu adanya sistem pemasaran yang lebih efektif untuk memperluas jangkauan pemasaran kopi Galunggung.

Strategi rantai pemasaran tradisional meliputi Lembaga pemasaran yang terlibat terdiri dari petani, tengkulak, pedagang pengumpul desa, pedagang besar, pedagang kecil (toko/kafe, dan konsumen). Pemasaran kopi yang umum dilakukan yaitu saluran pemasaran untuk konsumsi didaerah produksi yaitu untuk pasar eceran lokal dan industri pengolah didaerah produksi (Sugiarti, 2010). beberapa hal yang perlu diperhatikan dalam strategi pemasaran kopi menghadapi isu global adalah strategi internal (ke dalam negeri) berupa konversi tanaman pengembangan kopi arabika, dan peningkatan konsumsi domestik; serta strategi eksternal (ke luar negeri) dengan menjaga pangsa pasar, terobosan pasar baru, dan pengembangan kerjasama bilateral dan multilateral.

Menurut (Fahmi et al., 2013) faktor-faktor internal pemasaran yang mempengaruhi di industri kopi adalah : kualitas, promosi, harga, karyawan, pangsa pasar, tempat lokasi, teknologi dan sumber daya manusia. Faktor kelemahan yang dimiliki oleh industri antara lain faktor tempat lokasi, teknologi dan sumber daya manusia. Faktor-faktor ekternal pemasaran yang mempengaruhi di industri kopi yaitu faktor peluang dengan sub faktor kemudahan memperoleh bahan baku, permintaan terhadap kopi meningkat, adanya mitra kerja baru, meningkatnya pemasaran produk kopi olahan, dan model pemasaran yang semakin dinamis, sedangkan faktor yang menjadi ancaman adalah peraturan pemerintah, stabilitas ekonomi, banyaknya produk palsu di pasaran, dan banyaknya pesaing (Fattarani \& Iskandar, 2017).

Peluang untuk pengembangan perkopian Indonesia ditunjukkan juga oleh hasil penelitian (Sujiwo, Wahyuningsih, \& Supardi, 2009) yang menyatakan bahwa profitabilitas mengalami kenaikan dari petani kopi 
secara finansial dan ekonomi di seluruh wilayah pengamatan mengalami keuntungan. Dengan demikian perkebunan kopi rakyat di Indonesia layak untuk diteruskan dan secara ekonomi perkebunan kopi rakyat mampu berjalan secara efisien. Produk kopi dan olahannya mempunyai daya saing kuat, baik di dalam maupun di luar negeri dibutuhkan pengetahuan secara rinci preferensi konsumen yang berkembang, termasuk meningkatnya tuntutan konsumen akan informasi nutrisi serta jaminan kesehatan dan keamanan produk-produk pertanian (Mitra, 2013).

e-commerce menjadi tren terbaru yang menjadi strategi dalam melakukan pemasaran yang memanfaatkan teknologi untuk menjangkau cakupan yang lebih luas dibandingkan dengan pemasaran konvensional (Mitra, 2013). Pemanfaatan teknologi terutama internet menjadi sebuah kebutuhan kebanyakan individu, hal ini menjadi celah untuk melakukan pemasaran yang lebih efektif dan efisien. Terdapat beberapa tipe e-commerce yaitu Business to Business yang melibatkan dua pelaku bisnis , Business to Consumer yang melibatkan pelaku bisnis dengan konsumen dan Consumer to consumer yang melibatkan antar dua konsumen
(Sheikh \& Basti, 2015; Tamilarasi \& Elamathi, 2017).

\section{METODE PENELITIAN}

Penelitian ini dilakukan pada petani dan pemasar kopi galunggung di daerah parentas yang dilakukan selama 7 bulan dari bulan April-November. Pada penelitian ini dilakukan beberapa Langkah penelitian sebagai berikut :

\section{- Analisis Kebutuhan Penelitian}

Tahapan analisis kebutuhan merupakan langkah awal untuk mempersiapkan segala kebutuhan yang berkaitan dengan uji coba yang akan dilakukan. Uji coba yang akan dilakukan adalah melakukan pemasaran kopi galunggung dengan cara konvensional dan cara pemasaran yang memanfaatkan teknologi.

\section{- Perancangan}

Tahapan ini merupakan perancangan skenario yang akan dilakukan dalam melakukan uji coba pemasaran. Tahap ini dilakukan untuk memastikan tahapan implementasi berjalan dengan baik.

\section{- Perancangan Sistem Pemasaran \\ Konvensional}

Merancang skenario sistem pemasaran konvensional yaitu door to door, one to one relationship. 
- Perancangan Sistem Pemasaran E-

\section{Commerce}

Merancang skenario sistem pemasaran $e$-commerce yaitu pemasaran berbasis online dengan pemanfaatan media sosial, sistem informasi web dan media elektronik lainnya yang mendukung setiap sistem e-commerce.

\section{- Implementasi}

Tahap Implementasi merupakan tahap realisasi di lapangan sesuai dengan skenario yang sudah dirancang sebelumnya. Tahap ini dilakukan sesuai dengan jangka waktu yang telah ditentukan.

\section{- Pengujian}

Tahapan selanjutnya adalah pengujian yang dilakukan dengan bentuk angket dengan konsumen sebagai responden. Setelah penyeberan angket, kemudian dilakukan pengumpulan data yang nantinya data yang dihasilkan menjadi bahan untuk analisis.

\section{- Analisis Data}

Data yang diperoleh kemudian diolah dan dianalisis untuk dihitung. Pada tahap ini dilakukan komparasi data antara sistem pemasaran konvensional dengan sistem pemasaran e-commerce.

\section{- Hasil}

Tahap ini merupakan tahapan akhir untuk mencapai kesimpulan terkait dengan hasil analisis.

Hasil penelitian yang ditargetkan berupa pengembangan sistem pemasaran dengan pemanfaatan e-commerce.

\section{HASIL DAN PEMBAHASAN}

\section{- Analisis Kebutuhan Penelitian}

Pada pengembangan pemasaran kopi memerlukan beberapa kebutuhan untuk mendukung dalam melakukan penelitian. Kebutuhan yang diperlukan adalah kebutuhan perangkat keras, kebutuhan perangkat lunak, dan kebutuhan sumber daya manusia.

\section{Kebutuhan Perangkat Keras}

Kebutuhan perangkat keras merupakan alat untuk yang digunakan untuk membantu penelitian berupa perangkat keras. Berdasarkan analisis, terdapat beberapa kebutuhan perangkat keras dalam pelaksanaan penilitian yaitu :

\section{- Kopi}

Kopi merupakan alat utama dalam penelitian yang akan dilakukan pemasaran. Kopi yang digunakan adalah kopi galunggung yang dipetik langsung dari perkebunan dengan ketinggian 1200 mdpl. Varietas kopi 
yang terdapat di daerah parentas ini adalah kopi arabika.

\section{- Kemasan}

Pemasaran kopi dilakukan dengan menggunakan kemasan dan label produk sebagai identitas kopi, sehingga bisa menciptakan branding pada produk. Kemasan yang diperlukan untuk pengemasan kopi mempunyai bahan yang tahan terhadap keadaan diluar kemasan yang bisa menyebabkan perubahan rasa dan aroma kopi.

- Alat Roasting

Kopi yang masih hijau kemudian di roasting dengan menggunakan alat roasting khusus kopi agar bisa dipasarkan.

\section{- Komputer dan Smartphone}

Komputer dan Smartphone merupakan alat bantu dalam pemasaran berbasis e-commerce dengan menggunakan media sosial. Komputer dan Smartphone yang dipakai mempunyai spesifikasi seperti pada tabel berikut :

Tabel 1. Spesifikasi Komputer

\begin{tabular}{llll}
\hline No & Perangkat & Spesifikasi & \\
\hline 1 & Prossesor & Intel Celeron & CPU \\
& & N2840 2,16 GHz & \\
2 & RAM & 2 Gigabyte & \\
3 & Harddisk & 320 Gigabyte & \\
4 & OS & Windows 7 & \\
\hline
\end{tabular}

Tabel 2. Spesifikasi Smartphone

\begin{tabular}{lllll}
\hline No & Perangkat & Spesifikasi & & \\
\hline 1 & Prossesor & Octa-core & 1.8 & $\mathrm{GHz}$ \\
& & Cortex-A53 & & \\
2 & RAM & 4 Gigabyte & & \\
3 & ROM & 64 Gigabyte & & \\
4 & OS & Oreo 8.1 & & \\
\hline
\end{tabular}

- Kamera

Kamera digunakan sebagai alat bantu untuk pengambilan gambar produk kopi yang nantinya menjadi media pemasaran produk. Kamera yang digunakan adalah kamera Sony A6400.

\section{Kebutuhan aplikasi}

Pemasaran berbasis e-commerce memerlukan alat bantu perangkat lunak untuk pemasaran yang dilakukan di dunia maya. Kebutuhan perangkat lunak pada penelitian pengembangan pemasaran kopi adalah media sosial yang mempunyai traffic tinggi di internet. Media sosial yang digunakan adalah facebook dan instagram yang mempunyai fitur promosi dalam aplikasinya.

\section{- Facebook}

Aplikasi facebook dipilih karena mempunyai traffic pengunjung terbanyak di dunia setelah google, sehingga dapat menjangkau pemasaran sesuai dengan kriteria yang diperlukan.

\section{- Instagram}

Aplikasi instagram dimiliki oleh facebook yang memberikan layanan 
sharing foto dan video. Instagram merupakan aplikasi yang refresentatif dalam pemasaran produk yang mencakup audio visual.

\section{Kebutuhan Sumber Daya Manusia}

Pemasaran dilakukan oleh orang yang mengerti produk kopi yang akan dipasarkan dan memahami penggunaan teknologi terutama pemakaian media sosial facebook dan isntagram.

\section{- Perancangan}

Tahap perancangan merupakan tahap melakukan rancangan kegiatan pemasaran produk yang akan dilakukan dengan cara konvensional dan berbasis $e$ commerce. Pada tahap ini dilakukan pembuatan bagan alur penelitian yang terdiri atas:

\section{Proses Awal Penelitian}

Perancangan pada proses awal penelitian adalah melakukan koordinasi dengan mitra dan petani kopi, serta pembuatan brand produk kopi yang akan dipasarkan. Gambaran umum rancangan proses awal penelitian seperti pada Gambar 1.

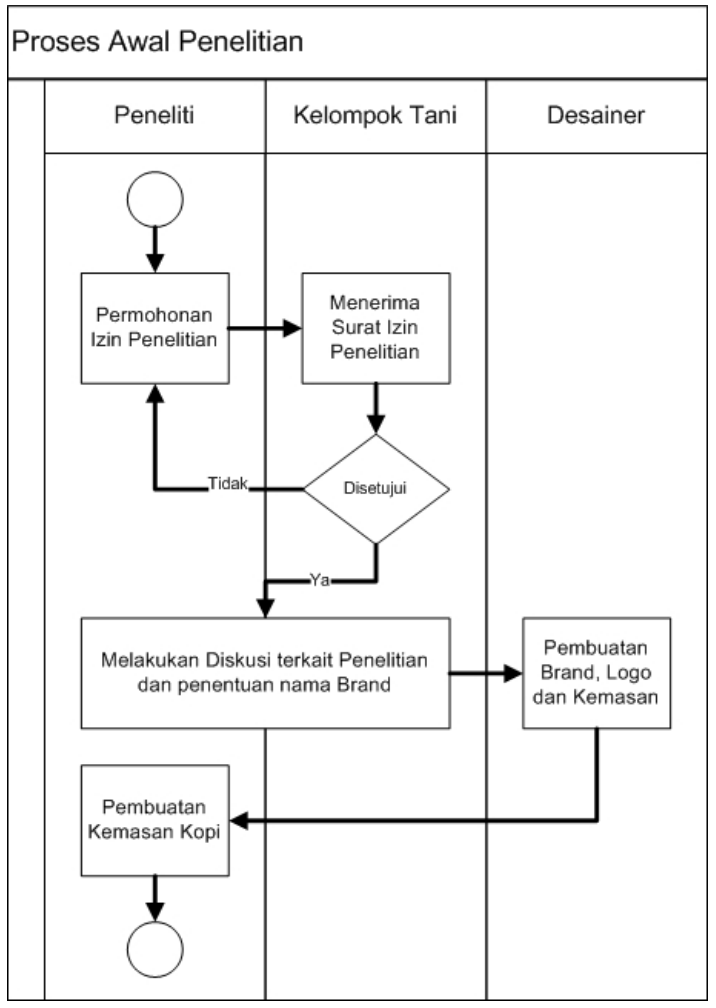

Gambar 1. Proses Awal Penelitian

\section{Proses Pengolahan}

Proses pengolahan kopi merupakan proses pengolahan dari hasil petik petani kopi (Cherry Bean) menjadi green bean dan kemudian menjadi roasted bean yang menjadi produk untuk dipasarkan. Rancangan proses pengolahan kopi seperti pada Gambar 2.

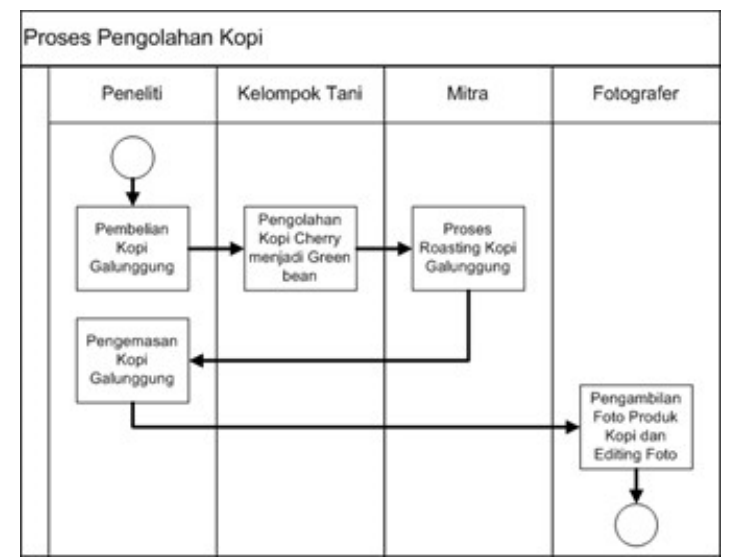

Gambar 2. Proses Pengolahan Kopi 


\section{Proses Pemasaran Konvensional}

Rancangan proses pemasaran konvensional menggunakan media poster dan brosur yang dibagikan kepada pelanggan coffee shop Balarea sebagai mitra penelitian. Rancangan proses pemasaran konvensional seperti pada Gambar 3.

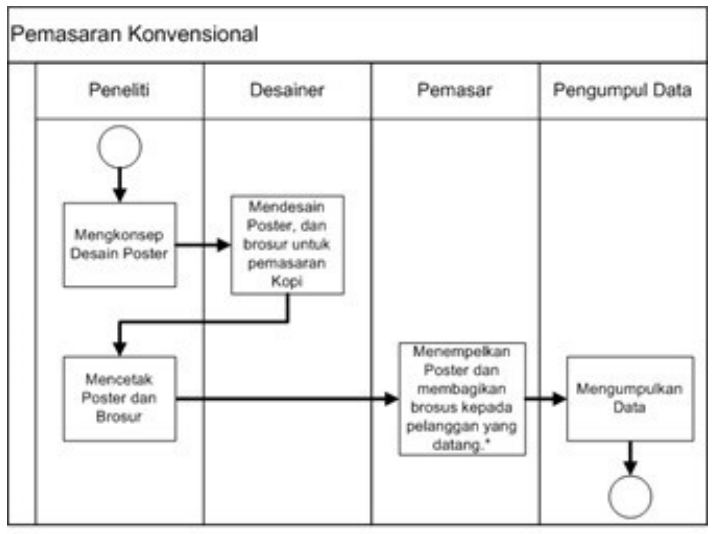

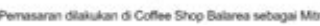

Gambar 3. Proses Pemasaran Konvensional

\section{Proses Pemasaran Berbasis $E$ -} Commerce

Proses pemasaran berbasis $e$ commerce menggunakan media sosial facebook dan instagram yang mempunyai fitur layanan pemasaran dan menjangkau banyak orang. Rancangan proses pemasaran berbasis e-commerce seperti pada Gambar 4.

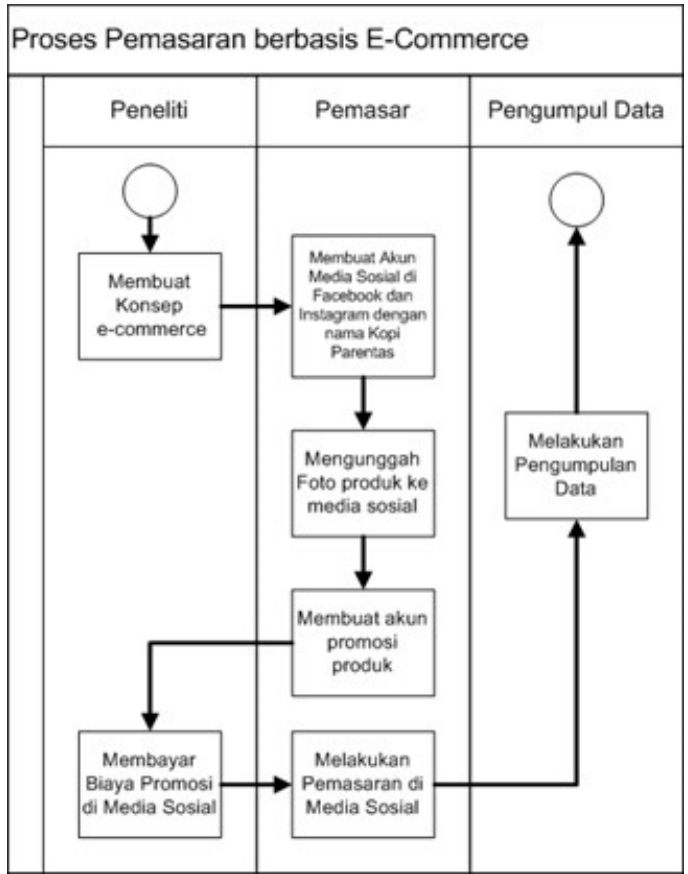

Gambar 4. Proses Pemasaran Berbasis $E$ Commerce

\section{- Implementasi}

\section{Proses awal penelitian}

Pada tahap ini peneliti mitra dan petani berdiskusi untuk penentuan brand yang akan di pasarkan. Berdasarkan hasil diskusi, nama brand yang dipakai adalah "Parentas Coffee" berdasarkan pada daerah tempat kopi ditanam. Pemakaian brand Parentas coffee juga mempunyai nilai pariwisata karena di daerah sana terdapat objek wisata. Setelah penentuan brand yang akan dipakai kemudian membuat kemasan dan label untuk produk kopi parentas coffee.

\section{Proses pengolahan kopi}

Pada proses pengolahan kopi, kopi masih berbentuk buah cherry yang masih terdapat kulit buah. Buah kopi cherry di 
kupas kemudian di bersihkan dengan metode Nature wash sehingga menjadi green bean. Kemudian tahap selanjutnya adalah proses roasting pada kopi agar bisa menjadi prosuk yang bisa di jual. Proses roasting menggunakan alat roasting yang dapat menampung 5 kilogram biji kopi. Proses roasting dilakukan oleh mitra coffee shop balarea seperti pada gambar 5 .

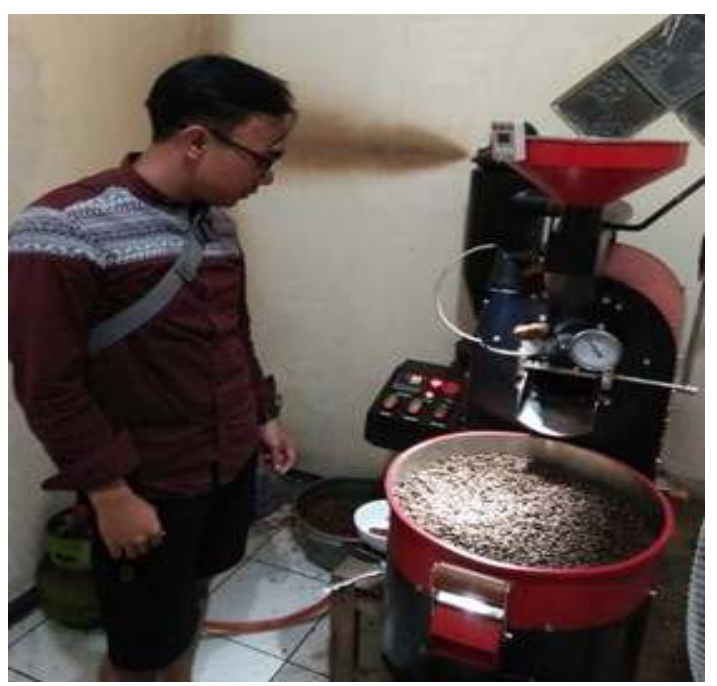

Gambar 5. Proses Roasting Kopi

Kopi yang telah melalui proses roasting kemudian dilakukan pengemasan kopi dengan kemasan yang telah dibuat. Kemasan kopi yang telah dikemas seperti pada Gambar 6.

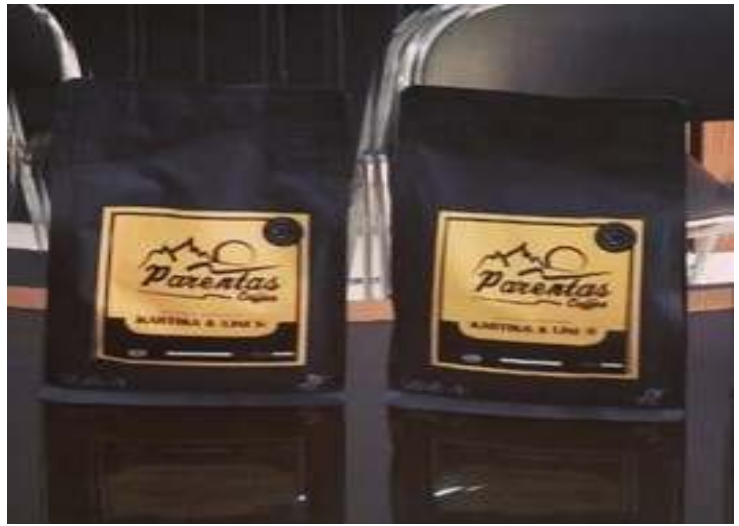

Gambar 6. Pengemasan Kopi

Kemasan kopi selanjutnya dilakukan pengambilan gambar untuk kebutuhan pemasaran yang akan dilakukan. Berikut contoh foto produk yang akan dipasarkan.

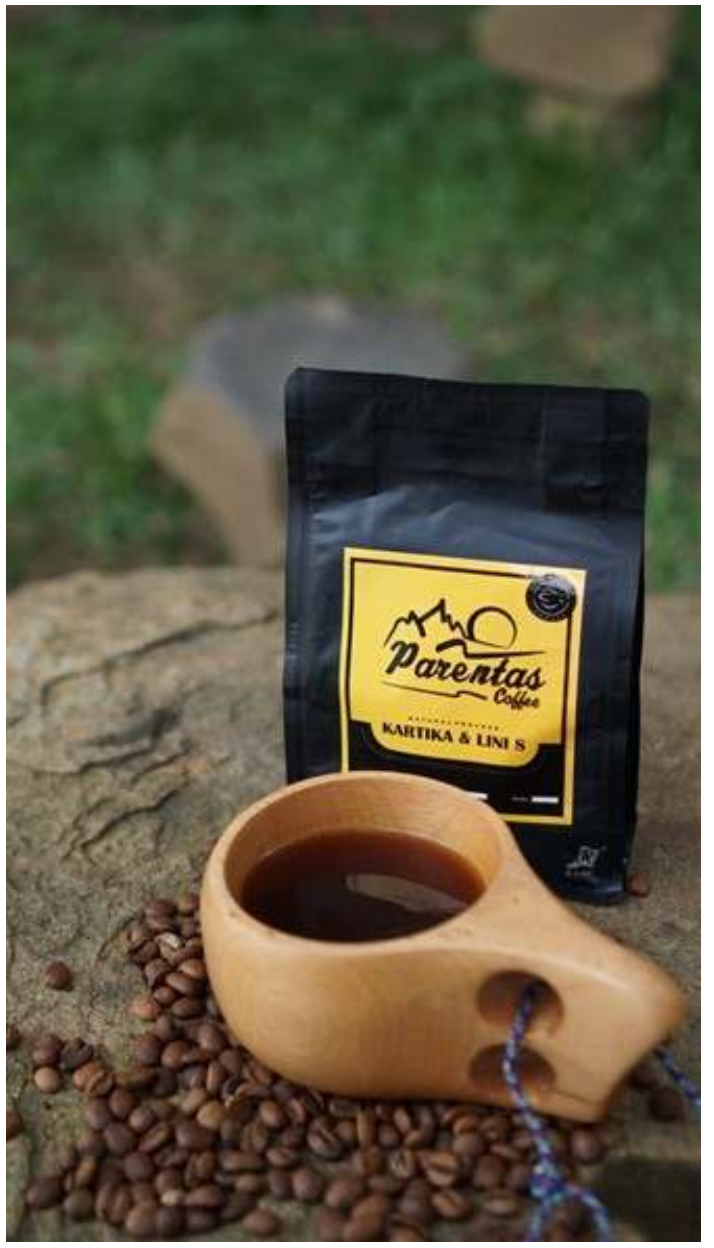

Gambar 7. Contoh Hasil Foto Produk 


\section{Proses pemasaran konvensional}

Pada proses pemasaran

konvensional pemasar melakukan pembuatan poster dan pemberian pamflet kepada pelanggan yang datang ke coffee shop balarea serta membagikan Sticker dengan brand "Parentas Coffee" seperti pada Gambar 8.

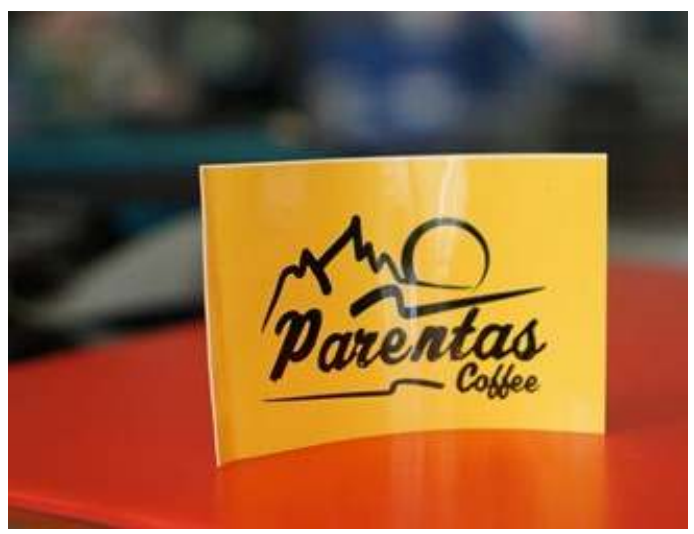

Gambar 8. Sticker Parentas Coffee

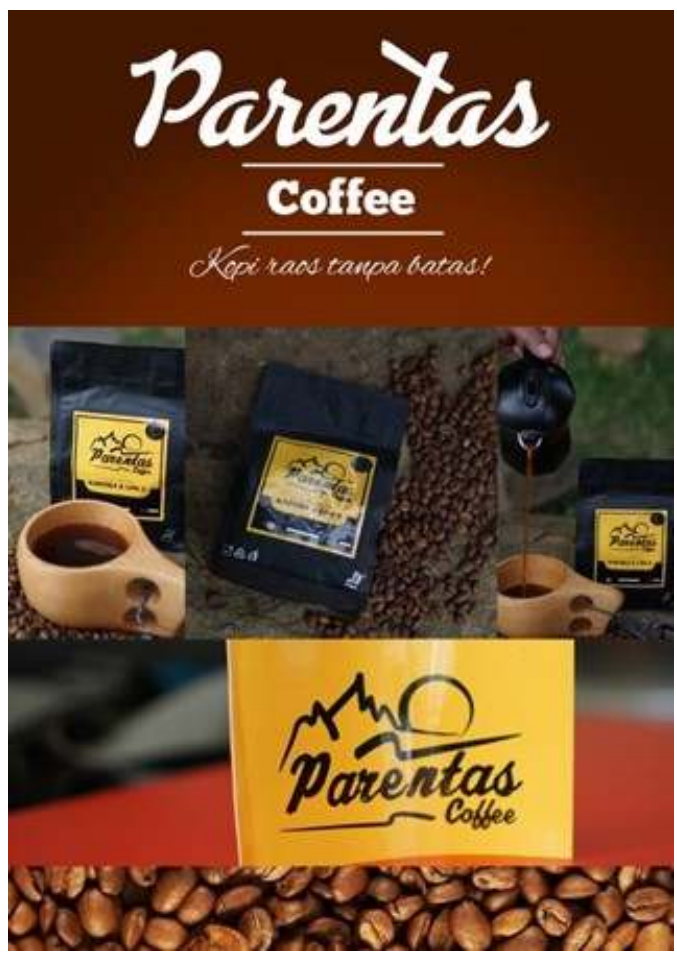

Gambar 9. Poster Pemasaran Kopi Parentas

\section{Pemrosesan pemasaran berbasis e-} commerce

Pada proses pemasaran berbasis ecommerce dilakukan pembuatan akun facebook dan instagram sebagai media pemasaran produk. Seperti pada Gambar 10.

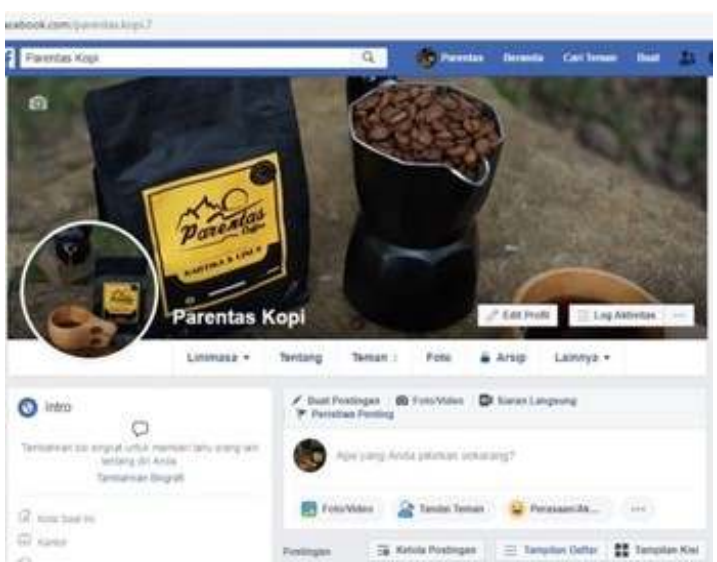

Gambar 10. Akun Facebook Parentas Kopi

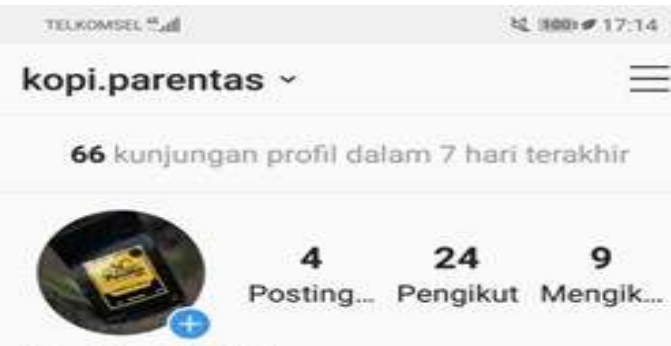

Kopi Parentas Galunggung

Produk/Layanan

Arabica coffee yang diambil langsung dari petani di daerah Parentas

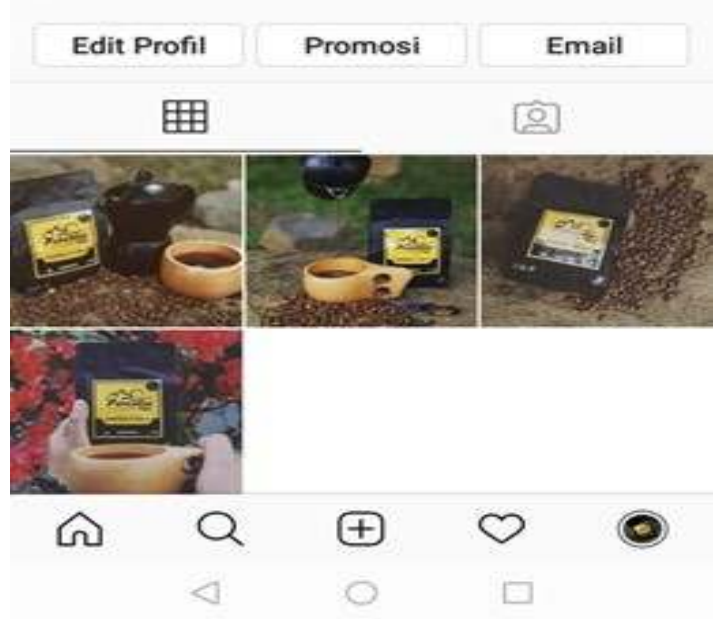

Gambar 11. Pembuatan Akun Instagram 


\section{- Pengujian}

Proses pengujian pemasaran berbasis e-commerce yang pertama adalah top up dana yang akan dikeluarkan untuk pemasaran kopi. Top up dilakukan di akun facebook saja, karena instagram telah terintegrasi dengan facebook. Pada tahap pengujian pemasaran dilakukan oleh tim pemasar.

\section{- Analisis Data}

Setelah melakukan pemasaran produk di media sosial kemudian masuk ke Analisis data yang didapatkan dari pemasaran produk berbasis e-commerce seperti pada Gambar 12.

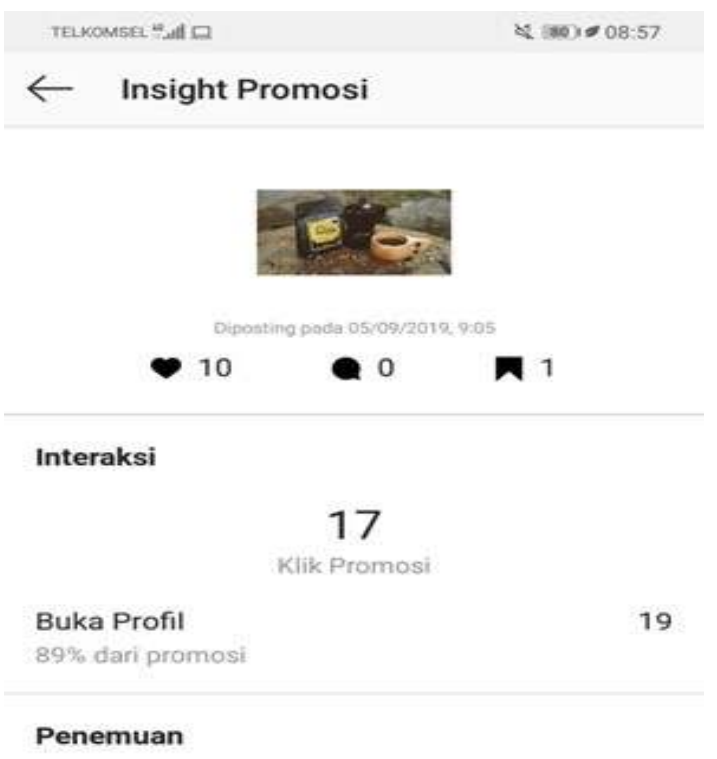

1.121

Orang Dijangkau $98 \%$ tidak mengikuti Anda $98 \%$ berasal dari promos! Anda

Impresi $82 \%$ dari promosi

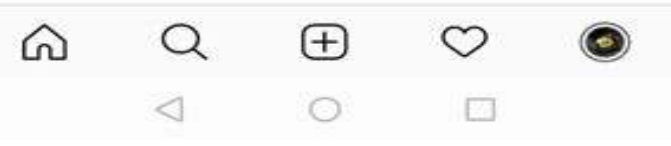

Gambar 12. Hasil Pemasaran Produk
Berdasarkan pada hasil pemasaran produk di media sosial, terdapat 1.121 orang melihat iklan produk parentas, dan 98\% dari akun yang tidak mengikuti akun parentas kopi. Jadi, pemasaran produk kopi mencakup akun yang tidak dikenal yang mempunyai ketertarikan pada kopi.
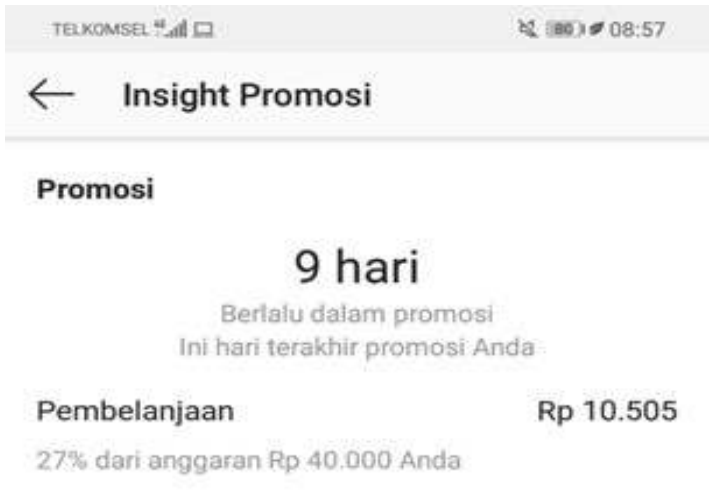

\section{Pemirsa}

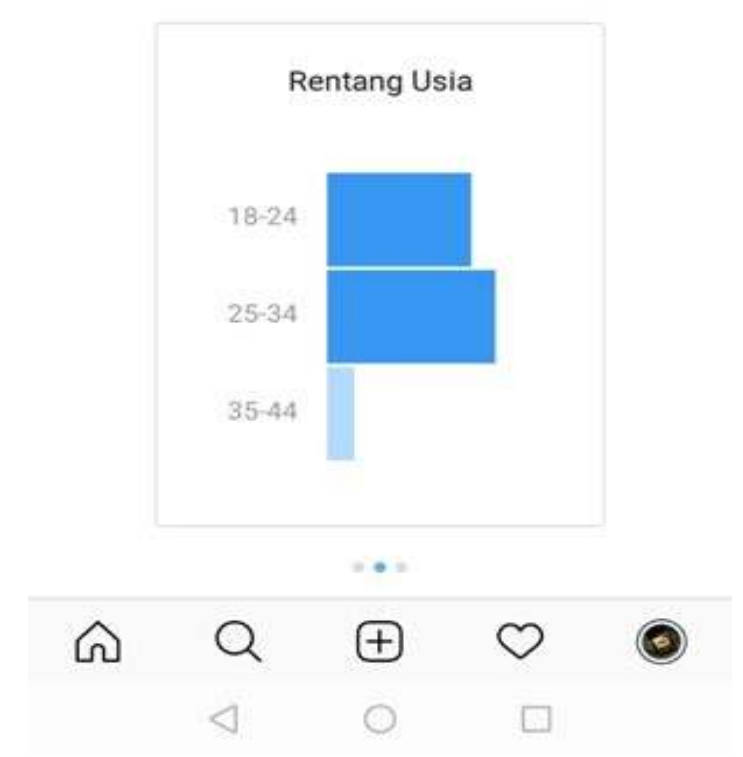

Gambar 13. Gambar Hasil Pemasaran Produk

Pada gambar 13 terdapat hasil range usia yang melihat iklan produk di media sosial. Umur 24-34 mempunyai ketertarikan lebih terhadap kopi menyusul umur 18-24 yang mempunyai 
ketertarikan terhadap kopi serta umur 3544 sedikit mempunyai ketertarikan terhadap kopi. Maka untuk melakukan pemasaran lebih baik di range usia 24-34.

\section{KESIMPULAN DAN SARAN}

Pemasaran produk kopi di sistem $e$ commerce meliputi akun yang tidak diketahui yang memiliki minat pada kopi. ada hasil dari rentang usia yang melihat iklan produk di media sosial. Usia 24-34 memiliki lebih banyak minat pada kopi, usia 18-24 yang memiliki minat kedua terbanyak pada kopi dan berusia 35-44 memiliki sedikit minat dalam kopi. Jadi untuk melakukan pemasaran kopi lebih baik dipasarkan untuk kisaran usia 24-34.

\section{UCAPAN TERIMA KASIH}

Penulis mengucapkan terimakasih kepada Dikti yang telah memeberikan dana hibah untuk penelitian ini serta balarea coffee yang menjadi mitra dan membantu untuk memasarkan kopi galunggung

\section{DAFTAR PUSTAKA}

Fahmi, M., Baihaqi, A., \& Kadir, I. A. (2013). Analisis Strategi Pemasaran Kopi Arabika 'Bergendaal Koffie' Di Kabupaten Bener Meriah. Agrisep, 14(1).
Fattarani, A. A., \& Iskandar, E. (2017). Studi Kasus: Usaha “ Kampung Kupi Gayo ", Kabupaten Aceh Tengah (Business Development Strategies Arabica Coffee Processing Case Study: “ Kampung Kupi Gayo ", Aceh Tengah Regency). Jurnal Ilmiah Mahasiswa Pertanisan Unsyiah, 2(4), 323-332.

Mitra, N. C. (2013). Analisis Peluang Pilihan Saluran Pemasaran Kopi Rakyat di Kecamatan Sumberbaru Kabupaten Jember. PT. Elex Media Komputindo.

Sheikh, S. M., \& Basti, M. (2015). Customer Satisfaction in Business to Consumer (B2C) E-commerce: A Comparative Study of Turkey and Pakistan. Eurasian Journal of Business and Economics, 8(16), 73-100.

https://doi.org/10.17015/ejbe.2015. 016.05

Sugiarti, S. (2010). Bermani Ulu Raya Kabupaten Rejang Lebong (Analysis of Coffee Marketing in Bermani Ulu Raya Subdistrict, District Rejang Lebong) Sri Sugiarti Jurusan Sosial Ekonomi Pertanian Fakultas Pertanian Universitas Bengkulu. Agrisep, 9, 130-136.

Sujiwo, J. T., Wahyuningsih, S., \& Supardi, S. (2009). Efisiensi Pemasaran Kopi (Coffea sp) Di Kecamatan Singorojo Kabupaten Kendal Joko. Mediagro, 5(2), 7285.

Tamilarasi, R., \& Elamathi, N. (2017). ECommerce- Business- TechnologySociety. Ijetmr, 4, 33-41. https://doi.org/10.5281/zenodo.104 2456 